\title{
The health insurance industry: perpetuating the opioid crisis through policies of cost-containment and profitability
}

\section{Michael E Schatman' \\ Lynn R Webster ${ }^{2}$}

'Foundation for Ethics in Pain Care, Bellevue, WA, USA; 'PRA Health

Sciences, Salt Lake City, UT, USA
Correspondence: Michael E Schatman Foundation for Ethics in Pain Care, I60I II4th Avenue, SE, Suite 100, Bellevue,WA 98004, USA

Email headdock@comcast.net

\author{
This article was published in the following Dove Press journal: \\ Journal of Pain Research \\ 18 March 2015 \\ Number of times this article has been viewed
}

\begin{abstract}
"People don't trust private health insurance companies for all the right reasons." Senator Bernie Sanders.

Throughout the world, industrialized nations look at the USA and are befuddled by its opioid crisis. Between 1999 and 2011, we witnessed the number of opioid deaths in the USA increase from 4,030 to $16,917,{ }^{1}$ with these figures having seemingly stabilized over the past several years. ${ }^{2}$ Many agree regarding the root causes of the crisis, with an analysis by Webster et $\mathrm{al}^{3}$ identifying health comorbidities (most prominently substance use disorders), payer policies mandating methadone as a firstline treatment option, physician error due to a lack of knowledge, patient nonadherence, unanticipated medical and mental health issues, concomitant utilization of other central nervous system depressants such as benzodiazepines, and sleep-disordered
\end{abstract} breathing as contributory.

One contributor to the opioid crisis that Webster et $\mathrm{al}^{3}$ failed to discuss was fraudulent marketing regarding the safety of certain opioid analgesics. For example, while Purdue Pharma claimed that the risk of addiction to its original formulation of OxyContin ${ }^{\circledR}$ was less than $1 \%,{ }^{4}$ in 2008 alone, the number of new nonmedical users of OxyContin aged 12 years or older was estimated at half a million. ${ }^{5}$ This is not to suggest that all nonmedical users are addicted or that other opioid analgesics have not been inappropriately promoted, but rather that Purdue Pharma's biased promotion of OxyContin was certainly the most visible and publicized of such marketing efforts.

Much has been done over the past several years in order to mitigate the opioid crisis in the USA. Some of the measures that have been taken appear to have been effective, while others have been ineffectual. Some, we posit, have actually been blatantly harmful to patients with pain, and, accordingly, to society.

One such measure has been prescription drug monitoring programs (PDMPs), which have been either implemented or passed into law in every state other than Missouri. ${ }^{6}$ However, data indicate that in most states, use of PDMPs by providers is "rare", and accordingly, PDMPs cannot be considered to be efficacious in their current forms. ${ }^{7}$

Another tactic to stem the tide of opioid overdoses and deaths has been state legislation that requires all patients receiving opioids to sign "treatment agreements". For example, the state of Indiana passed a law late in 2013 requiring that such agreements are signed by all patients receiving opioids outside of palliative care settings for more than 3 consecutive days. " "Treatment agreements", also known as "opioid agreements" and "opioid contracts", have been considered part of "universal precautions" since 
the seminal paper by Gourlay et al was published in $2005 .{ }^{9}$ However, there is no evidence that an agreement has had any effect on stifling opioid abuse; furthermore, addicted people are likely to agree to sign anything if it results in access to their substance(s) of abuse.

Urine drug testing is also a part of universal precautions that has its advocates ${ }^{10}$ and, more recently, its detractors. ${ }^{11}$ Unfortunately, while urine drug testing makes a considerable degree of common sense, the empirical evidence regarding its efficacy in reducing prescription opioid abuse is limited, as determined by systematic reviews. ${ }^{12,13}$

Many also believe that improving physician understanding of the potential dangers of opioid analgesics is an effective means of reducing opioid aberrancy, overdoses, and deaths. ${ }^{14}$ Some have opined that improving physician education regarding the overall treatment of pain is likely to be helpful. ${ }^{15}$ This may be true, although there is a dearth of empirical data supporting even mandatory pain continuing medical education's positive impact on opioid prescribing patterns. It has been noted that mandatory pain medical education regarding opioids fails to address the real causes of prescription opioid abuse, ${ }^{16}$ and until states with mandatory pain continuing medical continuing education requirements are able to empirically establish that they save lives, the impact of their efforts remains presumptive.

Another nonempirically-based approach to solving the prescription opioid abuse and overdose problem in the USA has been state policy and systems-level interventions pertaining to what constitutes "appropriate" dosages of opioids. A recent review ${ }^{17}$ of such approaches concluded that while such efforts are important, the data supporting them are "limited and inconsistent". The authors of the review note the importance of improving the evidence bases, requiring improvements before such approaches are considered a requisite for making broad policy and practice decisions based upon them. Among such interventions are state-mandated efforts to limit the amounts of opioids prescribed, often in terms of a morphine-equivalent daily dosage. A review of opioid guidelines ${ }^{18}$ indicates considerable disagreement regarding upper dosing thresholds, with none of thresholds in any way evidence-based. Although a study in Washington State ${ }^{19}$ determined that the risk of overdose increased with higher dosages of opioid analgesics, most overdoses occurred at low to moderate dosages, as these are the dosages most likely to be prescribed. While some of the authors of the Washington State opioid dosing guideline that went into effect in 2007 noted the temporal contiguity between the implementation of the guideline and the state's decrease in prescription opioid mortality, ${ }^{20,21}$ they fail to mention that the guideline was written in a manner that had a clear "chilling effect" on providers and hospital systems - scaring them into abandoning opioid therapy altogether as an aspect of their pain management armamentaria. ${ }^{22}$ Beyond the 2007 guidelines, in 2010 Washington State proceeded to pass an even harsher law dictating how physicians can treat pain, with that law going into effect in 2011. While Franklin et $\mathrm{al}^{23}$ reported in 2013 that only a small percentage of providers had discontinued prescribing opioids for chronic noncancer pain, anecdotal reports within the clinical practice of the first author (MES) suggest that the actual figure is considerably higher.

We believe that most of these efforts to reduce prescription drug abuse are well intended and suspect they may have prevented overdose deaths and diversion, although measuring their efficacies as stand-alone strategies or as elements of a coordinated risk evaluation and management strategy is likely impossible. We propose another measure for more sustained, serious consideration. For a number of years, the pharmaceutical industry has understood that producing opioids in tamper-resistant/abuse-deterrent formulations (TR/ADFs) could potentially reduce their abuse and associated overdoses and deaths.

There is evidence that these formulations may work to reduce real-world abuse. In the 1970s, addicts learned that pentazocine, when mixed with an antihistamine and injected, produced euphoria similar to that associated with heroin. Sterling-Winthrop responded by creating and receiving US Food and Drug Administration (FDA) approval for a pentazocine-naloxone combination product, thereby developing the first ADF in 1982. Emergency room visits associated with pentazocine decreased rapidly. ${ }^{24}$ In 2010, Purdue Pharma voluntarily reformulated its extended-release oxycodone product, the drug most commonly associated with abuse and the opioid crisis. ${ }^{25}$ Initially, they were not permitted to market it as an ADF due to a lack of research supporting the claim. ${ }^{26}$ However, the subsequent research supporting its efficacy as an ADF has been compelling, ${ }^{27-30}$ and its approval by the FDA as the first opioid permitted to be labeled as an ADF was granted in 2013. ${ }^{31}$ Although Purdue Pharma's generous research budget has made their oxycodone ADF the most heavily investigated in terms of efficacy for deterring abuse, support ofTRFs of other opioid analgesics is also beginning to appear in the literature. ${ }^{32-34} \mathrm{As}$ TR/ADFs are proving effective in reducing opioid abuse and mortality, it has been suggested that all TR/ADFs are granted Schedule III status, while all non-TR/ADFs are provided with Schedule II status as a rational response to the opioid scheduling conundrum. ${ }^{35}$ 
The availability of TR/ADFs to significantly attenuate the US opioid crisis is not part of the agenda of the health insurance industry, the sole focus of which is on costcontainment and profitability. Schatman et al have written extensively regarding the role of the health insurance industry in perpetuating suboptimal pain care in the USA by refusing to cover interdisciplinary treatment programs, and the ethical implications of this decision. ${ }^{36-43}$ Despite their extremely strong evidence bases for clinical efficacy ${ }^{44} 47$ and empirical data supporting their cost-efficiency, ${ }^{48,49}$ the number of such programs in the USA has decreased from over 1,000 in $1999^{50}$ to fewer than 100 today outside the Veterans Administration. ${ }^{51}$ Not surprisingly, in nations where citizens' health and well-being are considered the responsibility of the government, the number of interdisciplinary pain programs has been growing steadily. ${ }^{51}$ It may not be a coincidence that the opioid crisis in the USA began at about the same time that the number of interdisciplinary programs began to precipitously decrease. Poitras noted that the change in general pain management practices during this period resulted in "a substantial and predictable impact on the available supply of prescription opioids available for diversion". ${ }^{22}$ One of the great benefits of interdisciplinary pain treatment programs is that their goals and outcomes include cessation of, or at least reduction in, opioid analgesic utilization. ${ }^{53-56}$

Part of the US opioid crisis was related to private and public insurers' decisions to designate methadone as a firstline drug for chronic pain, based only upon its extremely low cost. ${ }^{3}$ This insurance industry policy accompanied the involvement of methadone in approximately one third of all fatal prescription opioid deaths between the years 1999 and 2010 , despite the drug representing only $5 \%$ of all opioids prescribed (or 9\% based on 2010 data). ${ }^{57}$ We hope that with the release of the American Pain Society Methadone Safety Guidelines $^{58}$ and an American Academy of Pain Medicine position paper $^{59}$ last year that identified methadone's lack of efficacy in treating chronic pain and the established safety issues, methadone prescriptions for chronic pain will dramatically decrease. Irrespective, insurers can be expected to continue to look for ways to contain the costs associated with treating patients with chronic pain, with dollars taking precedence over regard to individual or societal well-being.

The costs of research and development of TR/ADFs are staggering, as is the case with many types of drugs. Given the opioid crisis, the FDA is particularly stringent in regard to the requirements for established safety and efficacy of all opioid products..$^{60}$ Accordingly, TR/ADFs are expensive. A number of authors have written about insurance carriers' unwillingness to cover TR/ADFs, ${ }^{61-63}$ with Brushwood et $\mathrm{al}^{64}$ expressing concern that a patient may require documentation of risk of abuse or even a diagnosis of addiction in order to receive third-party coverage. Indeed, a review of a cross-section of formularies ${ }^{65}$ determined that the reformulated continuous-release oxycodone is often excluded from private insurance formularies, irrespective of its strong empirical support for abuse deterrence. It is important to note that research has indicated that insurance carriers were reluctant to pay for the more expensive OxyContin even prior to its reformulation for enhanced safety, resulting in increased use and abuse of less expensive and more dangerous opioids. ${ }^{66}$ Ben-Joseph et a ${ }^{67}$ recently determined that access limitations of a pre-ADF and postADF formulation of an opioid due to prior authorization and tier change (ie, assigning more expensive medications higher co-pays) restrictions resulted in increased overall medical costs without any offset savings in pharmacy costs. Beyond the empirical findings, anecdotal reports of insurers' refusal to cover TR/ADFs abound. This has become particularly problematic in instances where physicians who are concerned with patient safety (and perhaps the integrity of their own practices) refuse to prescribe any opioids other than TR/ADFs. As is so often the case, the cost-containment and profitability "ethic" of the insurance industry results in unnecessary patient suffering, either through oligoanalgesia or individuals at high risk for aberrancy being prescribed less safe opioids.

Not only do TR/ADFs potentially save lives, but economic costs to society as well. Kirson et a ${ }^{68}{ }^{6}$ recently determined that the annual societal cost savings associated with the oxycodone ADF in the USA include annual medical cost savings of $\$ 430$ million and indirect societal savings of $\$ 605$ million annually, totaling over $\$ 1$ billion in savings per year. Their analysis did not include savings associated with the numerous other TRFs currently on the market, although it can be assumed that they, too, have resulted in substantial societal savings. As TR/ADFs are less "desirable" or "likable" among abusers ${ }^{69,70}$ they become less likely to be diverted. This is of great significance as research indicates that diversion accounts for as many as $63 \%$ of fatal prescription medication overdoses. ${ }^{71}$

In regard to TR/ADFs, Katz et al ${ }^{72}$ suggested that "Formulary controls that limit reimbursement can help ensure that higher risk opioids are not prescribed unless the risks outweigh the benefits". The question becomes, however, "risk to whom?" The insurance industry's frequent refusal to 
cover TR/ADFs is not particularly "risky" within their own profit-driven contexts. The data suggesting that approval of TR/ADFs would result in savings for insurers ${ }^{68}$ is ignored in many instances, illustrating that the health insurance industry is "penny wise and pound foolish". However, there exists another possible explanation for this self-defeating behavior - one that would also explain insurers' increasing refusal to pay for cost-effective interdisciplinary pain management programs. The insurance industry is aware of the data indicating that the average enrollee will switch insurance carriers every few years. ${ }^{73}$ Accordingly, their seemingly nonsensical policy of refusal to cover TR/ADFs may be more shrewdly calculated than appears on the surface. The extreme expense of paying for the treatment of prescription opioid abuse is certainly no secret, with a recent study indicating that tampering with opioid analgesics results in substantial increases in health care use. ${ }^{74}$ However, given the frequency with which enrollees switch carriers, it is quite possible that insurers are willing to take the chance that the next carrier will be forced to "pick up the pieces" of abuse and addiction. Given the substantial expense associated with treating chronic pain, ${ }^{75}$ would the insurer's bottom line not improve if these "expensive" enrollees were to simply expire?

Some states are trying to rein in the sole focus on profits. In the past several years, a small handful of states have passed legislation prohibiting insurers from engaging in "fail first" policies. These policies have encouraged the dispensing of generic (and in the case of opioids, non-TR/ADFs) medications even if the physician has stipulated that the patient should receive a branded medication. Nayak and Pearson ${ }^{76}$ have suggested that more than other cost-containment strategies, "fail first" policies result in significant ethical concerns. While these limited state actions should be commended, this egregious insurance industry practice continues in all but the eight states that have enacted legislation prohibiting or severely limiting this maleficent policy. ${ }^{77}$

In summary, in the interests of cost-containment and profitability, the health insurance industry has contributed to the opioid crisis in the USA by refusing to pay for therapies to reduce the harm associated with opioid prescribing. A better way to marry cost-containment with societal wellbeing is to support progressively safer delivery systems for the opioid analgesics that remain a crucial component of pain physicians' treatment armamentaria. Federal agencies such as the FDA and the Drug Enforcement Administration claim to have an interest in stemming the tide of opioid abuse. Perhaps it is time for the federal government to require health insurance carriers (including Medicare and Medicaid) to provide coverage for the opioid formulations that have the potential to substantially ameliorate the nation's persisting prescription opioid crisis.

\section{Disclosure}

Over the past year, MES has served on advisory boards for Mallinckrodt and Zogenix, and on the speakers' bureau of Mallinckrodt. Over the past year, LRW has consulted or received research grants from AstraZeneca, BioDelivery Sciences International, CVS Caremark, Depomed, Egalet, Grunenthal USA, Inspirion Pharmaceuticals, Insys Therapeutics, Jazz Pharmaceuticals, Kaleo, Mallinckrodt, Nektar, Nevro, Orexo, Proove Biosciences, Signature Therapeutics, Synchrony Healthcare, Teva, and Travena.

\section{References}

1. Centers for Disease Control and Prevention. Trends in drug-poisoning deaths involving opioid analgesics and heroin: United States, 1999-2012. Available from: http://www.cdc.gov/nchs/data/hestat/ drug_poisoning/drug_poisoning.htm. Accessed January 31, 2015.

2. Centers for Disease Control and Prevention. Prescription drug overdose in the United States: fact sheet. Available from: http://www.cdc.gov/ homeandrecreationalsafety/overdose/facts.html. Accessed January 31, 2015 .

3. Webster LR, Cochella S, Dasgupta N, et al. An analysis of the root causes for opioid-related overdose deaths in the United States. Pain Med. 2011;12 Suppl 2:S26-S35.

4. Meier B. Pain Killer: The Extraordinary and True Story of OxyContin. Emmaus, PA, USA: Rodale Press; 2003.

5. Substance Abuse and Mental Health Services Administration. Results from the 2008 National Survey on Drug Use and Health: National Findings. Rockville, MD, USA: Office of Applied Studies, NSDUH Series H-36, HHS Publication No SMA 09-4434; 2009.

6. Missouri Prescription Drug Monitoring Program NOW Coalition. Coalition News Release, November 24, 2014. Available from: http:// mopdmpnow.org/media/coalition-news-releases/. Accessed February 3, 2015.

7. Fleming ML, Chandwani H, Barner JC, Weber SN, Okoro TT. Prescribers and pharmacists requests for prescription monitoring program (PMP) data: does PMP structure matter? J Pain Palliat Care Pharmacother. 2013;27:136-142.

8. Indiana Register. Medical licensing board of Indiana. Emergency rule. LSA document 13-495E. Available from: http://www.in.gov/legislative/ iac/20131030-IR-844130495ERA.xml.pdf. Accessed February 25, 2015.

9. Gourlay DL, Heit HA, Almahrezi A. Universal precautions in pain medicine: a rational approach to the treatment of chronic pain. Pain Med. 2005;6:107-112.

10. Darnall DB, Schatman ME. Urine drug screening: opioid risks preclude complete patient autonomy. Pain Med. 2014;15:2001-2002.

11. Goldberg DS, Rich BA. Pharmacovigilance and the plight of chronic pain patients: in pursuit of a realistic and responsible ethic of care. Indiana Health Law Rev. 2014;11:83-122.

12. Arnold RM, Han PK, Seltzer D. Opioid contracts in chronic nonmalignant pain management: objectives and uncertainties. Am J Med. 2006;119:292-296.

13. Starrels JL, Becker WC, Alford DP, Kapoor A, Williams AR, Turner BJ. Systematic review: treatment agreements and urine drug testing to reduce opioid misuse in patients with chronic pain. Ann Intern Med. 2010;152:712-720. 
14. Schatman ME, Darnall BD. "Just saying no" to mandatory pain CME: how important is physician autonomy? Pain Med. 2013;14: $1821-1825$.

15. Thomas D, Frascella J, Hall T, et al. Reflections on the role of opioids in the treatment of chronic pain: a shared solution for prescription opioid abuse and pain. $J$ Intern Med. December 30, 2014. [Epub ahead of print.]

16. Cain J. Mandatory CME on opioid prescribing fails to address true causes of prescription drug abuse. Pain Med. 2013;14:1821-1822.

17. Haegerich TM, Paulozzi LJ, Manns BJ, Jones CM. What we know, and don't know, about the impact of state policy and systems-level interventions on prescription drug overdose. Drug Alcohol Depend. 2014;145:34-47.

18. Cheung CW, Qiu Q, Choi SW, Moore B, Goucke R, Irwin M. Chronic opioid therapy for chronic non-cancer pain: a review and comparison of treatment guidelines. Pain Physician. 2014;17:401-414.

19. Dunn KM, Saunders KW, Rutter CM, et al. Opioid prescriptions for chronic pain and overdose: a cohort study. Ann Intern Med. 2010;152:85-92.

20. Franklin GM, Mai J, Turner J, Sullivan M, Wickizer T, Fulton-Kehoe D. Bending the prescription opioid dosing and mortality curves: impact of the Washington State opioid dosing guideline. Am J Ind Med. 2012;55: 325-331.

21. Garg RK, Fulton-Kehoe D, Turner JA, et al. Changes in opioid prescribing for Washington workers' compensation claimants after implementation of an opioid dosing guideline for chronic noncancer pain: 2004 to 2010. J Pain. 2013;14:1620-1628.

22. Anson P. Death rate from painkiller overdoses drops in Washington State. National Pain Report. January 28, 2013. Available from: http:// nationalpainreport.com/death-rate-from-painkiller-overdoses-drops-inwashington-state-8818418.html. Accessed February 5, 2015.

23. Franklin GM, Fulton-Kehoe D, Turner JA, Sullivan MD, Wickizer TM. Changes in opioid prescribing for chronic pain in Washington State. J Am Board Fam Med. 2013;26:394-400.

24. Baum C, Hsu JP, Nelson RC. The impact of the addition of naloxone on the use and abuse of pentazocine. Public Health Rep. 1987;102: 426-429.

25. Cicero TJ, Inciardi JA, Muñoz A. Trends in abuse of OxyContin and other opioid analgesics in the United States: 2002-2004. J Pain. 2005;6: 662-672.

26. Moorman-Li R, Motycka CA, Inge LD, Congdon JM, Hobson S, Pokropski B. A review of abuse-deterrent opioids for chronic nonmalignant pain. $P$ T. 2012;37:412-418.

27. Severtson SG, Bartelson BB, Davis JM, et al. Reduced abuse, therapeutic errors, and diversion following reformulation of extended-release oxycodone in 2010. J Pain. 2013;14:1122-1130.

28. Butler SF, Cassidy TA, Chilcoat H, et al. Abuse rates and routes of administration of reformulated extended-release oxycodone: initial findings from a sentinel surveillance sample of individuals assessed for substance abuse treatment. J Pain. 2013;14:351-358.

29. Coplan PM, Kale H, Sandstrom L, Landau C, Chilcoat HD. Changes in oxycodone and heroin exposures in the National Poison Data System after introduction of extended-release oxycodone with abuse-deterrent characteristics. Pharmacoepidemiol Drug Saf. 2013;22:1274-1282.

30. Sessler NE, Downing JM, Kale H, Chilcoat HD, Baumgartner TF, Coplan PM. Reductions in reported deaths following the introduction of extended-release oxycodone (OxyContin) with an abuse-deterrent formulation. Pharmacoepidemiol Drug Saf. 2014;23:1238-1246.

31. US Department of Health and Human Services/Food and Drug Administration. FDA approves abuse-deterrent labeling for reformulated OxyContin. April 16, 2013. Available from: http://www.fda.gov/ newsevents/newsroom/pressannouncements/ucm348252.htm. Accessed February 6, 2015.

32. Vosburg SK, Jones JD, Manubay JM, Ashworth JB, Benedek IH, Comer SD. Assessment of a formulation designed to be crush-resistant in prescription opioid abusers. Drug Alcohol Depend. 2012;126: 206-215.
33. Vosburg SK, Jones JD, Manubay JM, Ashworth JB, Shapiro DY, Comer SD. A comparison among tapentadol tamper-resistant formulations (TRF) and OxyContin ${ }^{\circledR}$ (non-TRF) in prescription opioid abusers. Addiction. 2013;108:1095-1106.

34. Lavonas EJ, Severtson SG, Martinez EM, et al. Abuse and diversion of buprenorphine sublingual tablets and film. J Subst Abuse Treat. 2014;47: $27-34$.

35. Schatman ME, Darnall BD. A practical and ethical solution to the opioid scheduling conundrum. J Pain Res. 2014;7:1-3.

36. Schatman ME. The demise of multidisciplinary pain management clinics? Pract Pain Manag. 2006;6:30-41.

37. Schatman ME. The demise of the multidisciplinary chronic pain management clinic: bioethical perspectives on providing optimal treatment when ethical principles collide. In: Schatman ME, editor. Ethical Issues in Chronic Pain Management. New York, NY, USA: Informa Healthcare; 2007.

38. Schatman ME, Giordano J, Schatman ME. A crisis in pain care: an ethical analysis. Part 1. Facts, issues, and problems. Pain Physician. 2008;11:483-490.

39. Giordano J, Schatman ME. A crisis in chronic pain care: an ethical analysis. Part 3: Toward an integrative, multi-disciplinary pain medicine built around the needs of the patient. Pain Physician. 2008;11: 771-784.

40. Robinson JP, Leo R, Wallach J, McGough E, Schatman ME. Rehabilitative treatment for chronic pain. In: Stannard C, Kalso E, Ballantyne JC, editors. Evidence-Based Chronic Pain Management. Oxford, UK, USA: Blackwell Publishing; 2010;407-423.

41. Schatman ME. Interdisciplinary chronic pain management: perspectives on history, current status, and future viability. In: Ballantyne JC, Rathmell JP, Fishman SM, editors. Bonica's Management of Pain, 4th edition. Philadelphia, PA, USA: Lippincott, Williams \& Wilkins; 2010; $1523-1532$.

42. Schatman ME, Sullivan J. Whither suffering? The potential impact of tort reform on the emotional and existential healing of traumatically injured chronic pain patients. Psychol Inj Law. 2010;3:182-202.

43. Schatman ME. The role of the health insurance industry in perpetuating suboptimal pain management: ethical implications. Pain Med. 2011;12: 415-426.

44. Kitahara M, Kojima KK, Ohmura A. Efficacy of interdisciplinary treatment for chronic nonmalignant pain patients in Japan. Clin J Pain. 2006;22:647-655.

45. Turk DC, Swanson K. Efficacy and cost-effectiveness treatment for chronic pain: an analysis and evidence-based synthesis. In: Schatman ME, Campbell A, editors. Chronic Pain Management: Guidelines for Multidisciplinary Program Development. New York, NY, USA: Informa Healthcare; 2007;15-38.

46. Stanos S. Focused review of interdisciplinary pain rehabilitation programs for chronic pain management. Curr Pain Headache Rep. 2012;16: $147-152$.

47. Gatchel RJ, McGeary DD, McGeary CA, Lippe B. Interdisciplinary chronic pain management: past, present, and future. Am Psychol. 2014;69:119-130.

48. Turk DC. Clinical effectiveness and cost-effectiveness of treatments for patients with chronic pain. Clin J Pain. 2002;18:355-365.

49. Gatchel RJ, Okifuji A. Evidence-based scientific data documenting the treatment and cost-effectiveness of comprehensive pain programs for chronic nonmalignant pain. J Pain. 2006;7:779-793.

50. Anooshian J, Streltzer J, Goebert D. Effectiveness of a psychiatric pain clinic. Psychosomatics. 1999;40:226-232.

51. Schatman ME. Interdisciplinary chronic pain management: international perspectives. Pain: Clinical Updates. 2012:20(7):1-5.

52. Poitras G. OxyContin, prescription opioid abuse and economic medicalization. Medicolegal Bioethics. 2012;2:31-43.

53. Robbins H, Gatchel RJ, Noe C, et al. A prospective one-year outcome study of interdisciplinary chronic pain management: compromising its efficacy by managed care policies. Anesth Analg. 2003;97:156-162.

54. Okifuji A. Interdisciplinary pain management with pain patients: evidence for its effectiveness. Sem Pain Med. 2003;1:110-119. 
55. Bosy D, Etlin D, Corey D, Lee JW. An interdisciplinary pain rehabilitation programme: description and evaluation of outcomes. Physiother Can. 2010;62:316-326.

56. Murphy JL, Clark ME, Banou E. Opioid cessation and multidimensional outcomes after interdisciplinary chronic pain treatment. Clin J Pain. 2013;29:109-117.

57. Centers for Disease Control and Prevention: Vital signs: risk for overdose from methadone used for pain relief - United States, 1999-2010. MMWR Morb Mortal Wkly Rep. 2012;61:493-497.

58. Chou R, Cruciani RA, Fiellin DA, et al. Methadone safety: a clinical practice guideline from the American Pain Society and College on Problems of Drug Dependence, in collaboration with the Heart Rhythm Society. J Pain. 2014;15:321-337.

59. American Academy of Pain Medicine. The evidence against methadone as a "preferred" analgesic: a position statement from the American Academy of Pain Medicine; 2014. Available from: http://www.painmed. $\mathrm{org} /$ files/the-evidence-against-methadone-as-a-preferred-analgesic.pdf. Accessed February 19, 2015.

60. Brooks MJ. Mitigating the safety risks of drugs with a focus on opioids: are risk evaluation and mitigation strategies the answer? Mayo Clin Proc. 2014;89:1673-1684.

61. Passik SD. Issues in long-term opioid therapy: unmet needs, risks, and solutions. Mayo Clin Proc. 2009;84:593-601.

62. Schneider JP, Matthews M, Jamison RN. Abuse-deterrent and tamperresistant opioid formulations: what is their role in addressing prescription opioid abuse? CNS Drugs. 2010;24:805-810.

63. Romach MK, Schoedel KA, Sellers EM. Update on tamper-resistant drug formulations. Drug Alcohol Depend. 2013;130:13-23.

64. Brushwood DB, Rich BA, Coleman JJ, Bolen J, Wong W. Legal liability perspectives on abuse-deterrent opioids in the treatment of chronic pain. J Pain Palliat Care Pharmacother. 2010;24:333-348.

65. Argoff CE, Stanos SP, Wieman MS. Validity testing of patient objections to acceptance of tamper-resistant opioid formulations. J Pain Res. 2013;6:367-373.

66. Cicero TJ, Kurtz SP, Surratt HL, et al. Multiple determinants of specific modes of prescription opioid diversion. J Drug Issues. 2011;41: 283-304.

67. Ben-Joseph R, Chen CC, De AP, Wade RL, Shah D. Consequences of patient access restrictions to branded oxycodone hydrochloride extended-release tablets on healthcare utilization and costs in US health plans. J Med Econ. 2014;17:708-718.
68. Kirson NY, Shei A, White AG, et al. Societal economic benefits associated with an extended-release opioid with abuse-deterrent technology in the United States. Pain Med. 2014;15:1450-1454.

69. Butler SF, Fernandez KC, Chang A, et al. Measuring attractiveness for abuse of prescription opioids. Pain Med. 2010;11:67-80.

70. Cicero TJ, Ellis MS, Surratt HL. Effect of abuse-deterrent formulation of OxyContin. N Engl J Med. 2012;367:187-189.

71. Hall AJ, Logan JE, Toblin RL, et al. Patterns of abuse among unintentional pharmaceutical overdose fatalities. JAMA. 2008;300:2613-2620.

72. Katz NP, Birnbaum H, Brennan MJ, et al. Prescription opioid abuse: challenges and opportunities for payers. Am J Manag Care. 2013;19:295-302.

73. Brown ER, Lavarreda SA, Rice T, Kincheloe JR, Gatchell MS. The state of health insurance in California: findings from the 2003 California Health Interview Survey (August 2005). Available from: http:/ucla-devweb01.reliam.com/publications/Documents/PDF/The $\% 20$ State $\% 20$ of $\% 20$ Health $\% 20$ Insurance $\% 20$ in $\% 20$ California $\% 20$ Findings $\% 20$ from $\% 20$ the $\% 202003 \% 20$ California $\% 20$ Health $\% 20$ Interview $\% 20$ Survey.pdf. Accessed February 13, 2015.

74. Vietri J, Joshi AB, Barsdorf AI, Merdekian J. Prescription opioid abuse and tampering in the United States: results of a self-report survey. Pain Med. 2014;15:2064-2074.

75. Haas M, De Abreu Lourenco R. Pharmacological management of chronic lower back pain: a review of cost effectiveness. Pharmacoeconomics. January 22, 2015. [Epub ahead of print.]

76. Nayak RK, Pearson SD. The ethics of "fail first": guidelines and practical scenarios for step therapy coverage policies. Health Aff (Millwood). 2014;33:1779-1785.

77. Irwin JA, Hopkins T, Conford P, et al. Sign up to support legislation in the New York state legislature that seeks to regulate "first fail" or "step therapy" drug policies imposed by health insurance companies. Available from: http://www.epilepsyuny.org/Documents/Step\%20 Therapy\%20Advocacy\%20Pkg.\%2009\%2009\%2013.pdf. Accessed February 20, 2015.
Journal of Pain Research

\section{Publish your work in this journal}

The Journal of Pain Research is an international, peer-reviewed, open access, online journal that welcomes laboratory and clinical findings in the fields of pain research and the prevention and management of pain. Original research, reviews, symposium reports, hypothesis formation and commentaries are all considered for publication.

\section{Dovepress}

The manuscript management system is completely online and includes a very quick and fair peer-review system, which is all easy to use. Visit http://www.dovepress.com/testimonials.php to read real quotes from published authors. 